\title{
Mathematical Modelling of One-Dimensional Overland Flow on a Porous Surface
}

\author{
Ai Sher Tah ${ }^{1}$, How Tion Puay ${ }^{1 *}$ and Nor Azazi Zakaria ${ }^{1}$ \\ ${ }^{1}$ River Engineering and Urban Drainage Research Centre (REDAC), Universiti Sains Malaysia, Seri \\ Ampangan, 14300 Nibong Tebal, Penang, Malaysia.
}

\begin{abstract}
Due to rapid urbanization, surface water drainage systems are designed to perform as natural drainage acting as water storage areas that allow infiltration and evaporation and to solve issues caused by traditional drainage system As there is an increase of attention on Sustainable Urban Drainage system (SuDs) to manage storm water, a simple yet efficient numerical model for flow over porous media is needed. The purpose of this research is to develop a numerical model for the simulation of flow over porous media. The model solves the unsteady one-dimensional Saint-Venant equation for the surface flow. The advection term in the momentum equation is solved using the Constrained Interpolation Profile (CIP) scheme which is of the third order accuracy. Averaged infiltration rate is estimated from the physical model experiment. The model is then used to simulate dam-break flow over porous bed and the result is verified against the experiment. The author found that the numerical model performed satisfactorily in terms of surface flow profile and the loss of total fluid volume through infiltration.
\end{abstract}

\section{Introduction}

Sustainable Urban Drainage System (SuDs) is surface water drainage schemes designed to perform as a natural drainage overcoming the rapid development of Urbanisation. SuDS provide areas to store water in natural flow allowing infiltration to ground water or evaporation process to be happening on the surface water which will be a better way to solve issues caused by traditional drainage system [1].

SuDs that allow infiltration of surface water to the subsurface can help in attenuation of surface water. To prevent ground stability hazards and deterioration of groundwater quality, it is important to understand the mechanism of surface water infiltrate to the subsurface [2].

In Today's World, water resource management is becoming the main source of concern due to the extensive urbanization and climate changes. With technology, computer models with innovative approaches are required to design and implement Sustainable Urban Drainage System (SuDs) to optimized and meet the environmental and economic preconditions [3].

In this study, a mathematical model is developed using one-dimensional depthaveraged with higher order scheme to simulate flow over porous media, where porous media

\footnotetext{
* Corresponding author: redac puay@usm.my
} 
is used to represent the subsurface condition. To increase the accuracy of the numerical model, a third order numerical scheme, i.e. Constrained Interpolation Profile (CIP) [4] scheme is applied in this model to solve the advection term in the momentum equation. The numerical model is first verified against the one-dimensional dam break problem of perfect fluid. The numerical model is then used to simulate flow over porous media, by releasing a finite volume of water retained behind a gate onto porous bed. The infiltration rate is determined experimentally and used in the numerical model. The performance of the numerical model is validated against experimental results in terms of the reproduction of water surface profile.

\section{Numerical model}

\subsection{Governing equations}

The governing equations of the numerical model consist of the depth-averaged continuity and momentum equations as such,

Continuity Equation:

Momentum Equation:

$$
\frac{\partial h}{\partial t}+u \frac{\partial h}{\partial x}=-h \frac{\partial u}{\partial x}-\frac{q_{l}}{B}
$$

$$
\frac{\partial u}{\partial t}+u \frac{\partial u}{\partial x}=-g \frac{\partial h}{\partial x}-g n^{2} \frac{u|u|}{h^{\frac{4}{3}}}
$$

Here, $u$ is the depth averaged velocity, $h$ is the depth of flow, $q_{l}$ is the rate of infiltration, $B$ is width of the channel, $n$ is Manning's coefficient of roughness, and $g$ is the gravitational acceleration.

\subsection{Numerical algorithm}

Finite difference method is used based on the staggered mesh system shown in Figure 1. The governing equations are solved in two steps using the time-splitting method. In the first step, the advection terms in the continuity and momentum equations are solved using the CIP scheme as follows,

\section{Step 1:-}

Continuity Equation:

Momentum Equation:

$$
\frac{\partial h}{\partial t}+u \frac{\partial h}{\partial x}=0 \quad h^{n} \stackrel{\text { CIP }}{\rightarrow} h^{*}
$$

$$
\frac{\partial u}{\partial t}+u \frac{\partial u}{\partial x}=0 \quad u^{n} \stackrel{\text { CIP }}{\rightarrow} u^{*}
$$

The initial values $h^{n}$ and $u^{n}$ are updated to temporary values of $h^{*}$ and $u^{*}$ after solving the advection term with CIP scheme. 


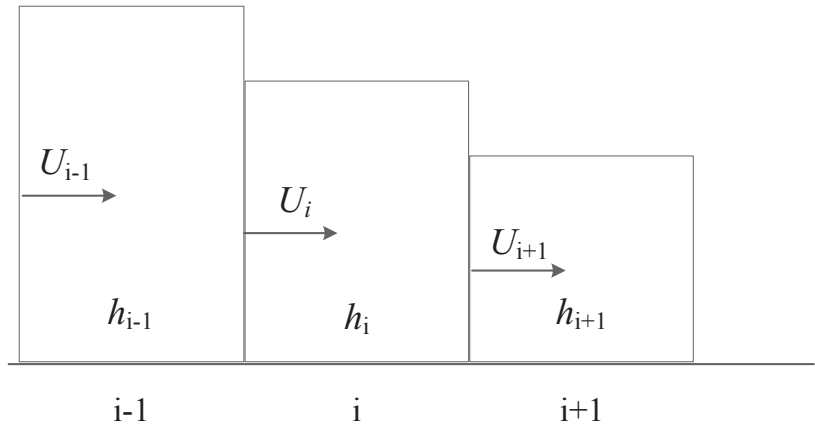

Fig. 1. Staggered mesh system diagram

\section{Step 2: -}

The remaining non-advection term in the continuity and momentum equation can be expressed as follows by using the temporary value of $h^{*}$ and $u^{*}$.

Continuity Equation:

$$
\frac{\partial h}{\partial t}=-h \frac{\partial u}{\partial x}-\frac{q_{l}}{B} \Rightarrow \frac{h_{i}^{n+1}-h_{i}^{*}}{\Delta t}=-h^{*}{\frac{\partial u^{n+1}}{\partial x}}^{n}-\left(\frac{q_{l}}{B}\right)^{n}
$$

Momentum Equation:

$$
\frac{\partial u}{\partial t}=-g \frac{\partial h}{\partial x}-g n^{2} \frac{u|u|}{h^{\frac{4}{3}}} \Rightarrow \frac{u_{i}^{n+1}-u_{i}^{*}}{\Delta t}=-g\left(\frac{\partial h}{\partial x}\right)^{n+1} g n^{2} \frac{u^{*}\left|u^{*}\right|}{h^{* \frac{4}{3}}}
$$

Based on Eq. (6), an initial guess value $\tilde{u}$ can be established as follows,

$$
\frac{\widetilde{u}_{i}-u_{i}^{*}}{\Delta t}=-g\left(\frac{\partial h}{\partial x}\right)^{*} g n^{2} \frac{u^{*}\left|u^{*}\right|}{h^{* \frac{4}{3}}}
$$

Subtracting Eq. 7 from Eq. 6 yields,

$$
\frac{u_{i}^{n+1}-\widetilde{u}_{i}}{\Delta t}=-g\left[\left(\frac{\partial h}{\partial x}\right)^{n+1}-\left(\frac{\partial h}{\partial x}\right)^{*}\right]=-g \frac{\partial}{\partial x}(\delta h)
$$

Where,

Therefore, from Eq. (8).

$$
\delta h=h^{n+1}-h^{*}
$$

Differentiating Eq.(10) with respect to $x$ yields,

$$
u_{i}^{n+1}=\tilde{u}_{i}-g \Delta t \frac{\partial}{\partial x}(\delta h)
$$

$$
\frac{\partial u_{i}^{n+1}}{\partial x}=\frac{\partial \widetilde{u}_{i}}{\partial x}-g \Delta t \frac{\partial^{2}}{\partial x^{2}}(\delta h)
$$

By substituting Eq. (11) into Eq. (5), the following Poisson equation can be derived.

$$
\frac{\delta h_{i}}{\Delta t}=-h^{*}\left[\frac{\partial \widetilde{u}_{i}}{\partial x}-g \Delta t \frac{\partial^{2}}{\partial x^{2}}(\delta h)\right]-\left(\frac{q_{l}}{B}\right)^{n}
$$


The Poisson equation in Eq.12 is solved with SOR (Successive Over Relaxation) method for $\delta h$.

Finally, the new value at the next time step, $h^{n+1}$ and $u^{n+1}$ can be updated based on Eq.(9) and Eq.(10) as follows,.

$$
\begin{gathered}
h^{n+1}=h^{*}+\delta h \\
u_{i}^{n+1}=\tilde{u}_{i}-g \Delta t \frac{\partial}{\partial x}(\delta h)
\end{gathered}
$$

\subsection{Verification of numerical model}

The numerical model is verified by simulating the release of a finite volume of water on an initially dry bed (or more commonly referred to as the dam-break flow model). The simulation result is compared to the analytical solution which was derived by Ritter [5]. The Ritter solution that can examine the numerical accuracy of the depth-averaged model is widely used to check the numerical solutions of the shallow water Equations (SWE) [6]. Figure 3 shows good agreement between the Ritter's solutions and the numerical result in terms of the water surface profile.

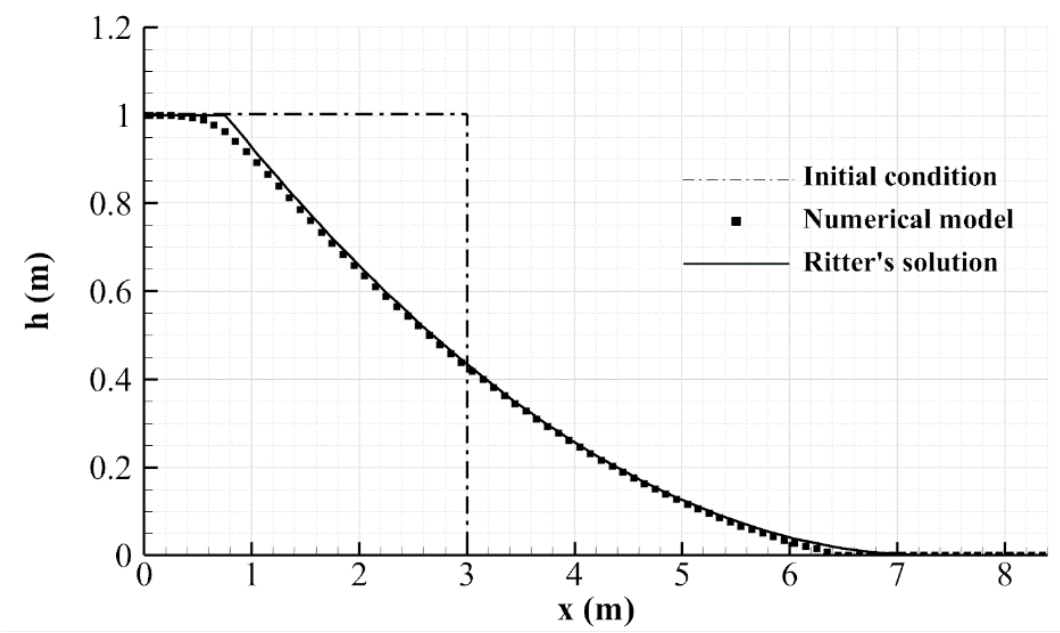

Fig. 2. Analytical and numerical solution for dam break flow over dry bed condition at time, $t=0.70 \mathrm{~s}$

\subsection{Simulation of flow over porous media}

The dam-break flow over porous media shown in Fig.2 is simulated in the numerical model. Simulation of a dam break flow problem was carried out to check the numerical simulation stability and accuracy of the model with higher-order schemes under the inclusion of infiltration in the porous zone. The infiltration rate used in the numerical model is evaluated from the experiment. The simulation conditons for the numerical model are shown in Table 1. 


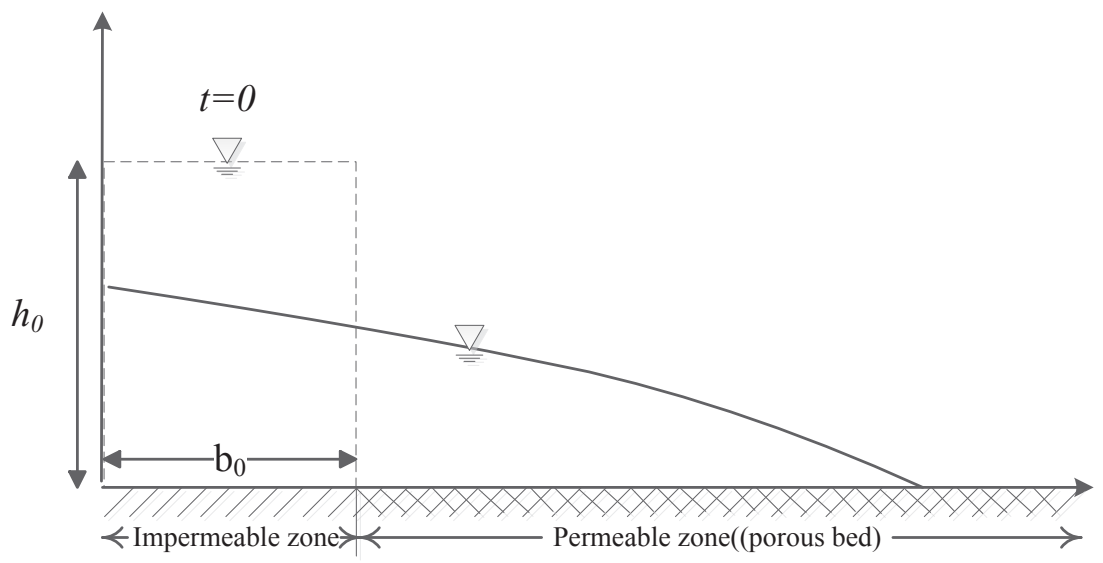

Fig. 3. Schematic diagram of dam break flow over media

Table 1. Simulation conditions table.

\begin{tabular}{|c|c|c|c|c|}
\hline Parameters & Case 1 & Case 2 & Case 3 & Case 4 \\
\hline$d x,[\mathrm{~m}]$ & 0.01 & 0.01 & 0.01 & 0.01 \\
\hline$d t,[\mathrm{~s}]$ & $1.0 \times 10^{-6}$ & $1.0 \times 10^{-6}$ & $1.0 \times 10^{-6}$ & $1.0 \times 10^{-6}$ \\
\hline$h_{0},[\mathrm{~m}]$ & 0.05 & 0.10 & 0.05 & 0.10 \\
\hline$b_{0},[\mathrm{~m}]$ & 0.3 & 0.3 & 0.3 & 0.3 \\
\hline Bead size, $d[\mathrm{~mm}]$ & 6 & 6 & 10 & 10 \\
\hline Infiltration rate, $\left[\mathrm{m}^{2} / \mathrm{s}\right]$ & 0.0099 & 0.0204 & 0.0105 & 0.0258 \\
\hline $\begin{array}{c}\text { Manning's roughness } \\
\text { coefficient, } n\end{array}$ & 0.05 & 0.05 & 0.05 & 0.05 \\
\hline
\end{tabular}

\section{Physical model experiment}

\subsection{Experimental setup}

A rectangular tank with the size of width $\left(b_{0}\right)=0.30 \mathrm{~m}$ and depth $=0.20 \mathrm{~m}$ are used to simulate dam-break flow over porous media with two different water depth $\left(h_{0}\right)$, which are $0.05 \mathrm{~m}$ and $0.10 \mathrm{~m}$. The porous zone is made up of single size glass beads with size of $\mathrm{d}=6 \mathrm{~mm}$ and $\mathrm{d}=10$ $\mathrm{mm}$. During the experiment, the instantaneous release of the water column is carried out by pulling up the gate in fast motion. Motion video of the dam-break flow is recorded and used to determine the flow profile and infiltration rate. The experiment conditions are summarized in Table 2. Meanwhile, the infiltration rate is determined as the slope of the linear line of the accumulated volume losses vs time, as shown in Fig. 4. The accumulated volume loss is determined graphically using the motion video frame.

Table 2. Experiment table.

\begin{tabular}{|c|c|c|c|}
\hline Experiment & $\mathbf{d}(\mathbf{m m})$ & $\mathbf{b}_{\mathbf{0}}(\mathbf{m})$ & $\mathbf{h}_{\mathbf{0}}(\mathbf{m})$ \\
\hline EXP 6-05 & 6 & 0.30 & 0.05 \\
\hline EXP 6-10 & 6 & 0.30 & 0.10 \\
\hline EXP 10-05 & 10 & 0.30 & 0.05 \\
\hline EXP 10-10 & 10 & 0.30 & 0.10 \\
\hline
\end{tabular}




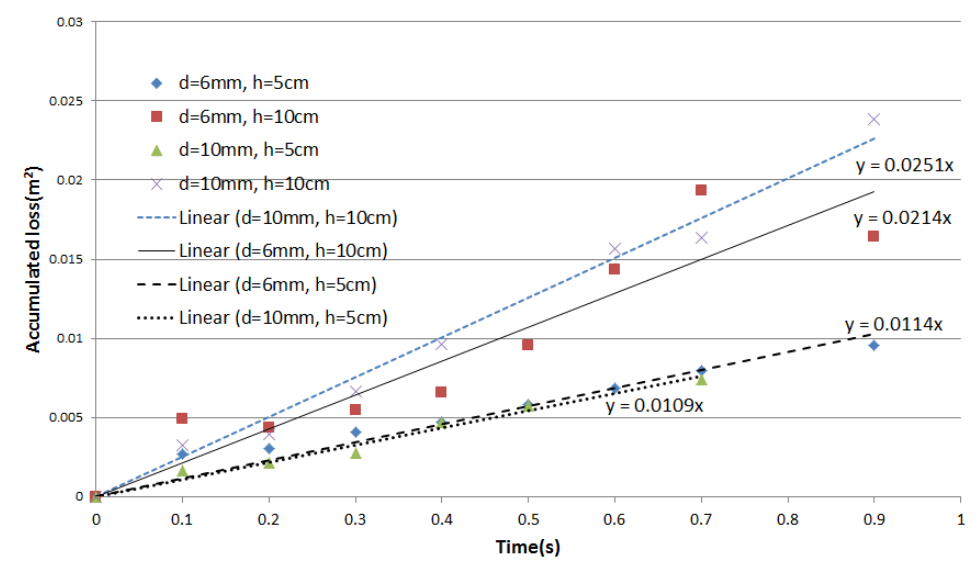

Fig. 4. Graph of accumulated volume losses.

\section{Result and discussion}

The result of the numerical simulation of the dam-break flow over porous media is compared against the experiment results as shown from Figure 5 to Figure $7\left(d=6 \mathrm{~mm}\right.$, and $h_{o}=$ $0.05 \mathrm{~m})$, from Figure 8 to Figure $10\left(d=6 \mathrm{~mm}\right.$, and $\left.h_{o}=0.10 \mathrm{~m}\right)$, from Figure 11 to Figure $13\left(d=10 \mathrm{~mm}\right.$, and $\left.h_{o}=0.05 \mathrm{~m}\right)$ and from Figure 14 to Figure $16\left(d=10 \mathrm{~mm}\right.$, and $h_{o}=$ $0.10 \mathrm{~m})$. Overall, the water surface profile produced by the numerical model agrees well with the experiment counterpart. This is true for both bead sizes of $6 \mathrm{~mm}$ and $10 \mathrm{~mm}$ under all cases. However, the water surface profile in the experiment at the initial stage (after the gate is pulled up) is different from the numerical result especially when in the case of higher initial water depth $\left(h_{o}=0.10 \mathrm{~m}\right)$ as can be seen in Figure 8 to Figure 10 and Figure 14 to Figure 16. This due to the effect of gate pulling, which is more noticeable for higher initial water depth behind the gate. Under same initial water depth of $h_{o}=0.10 \mathrm{~m}$, the effect of gate pulling is more obvious for bead size $d=6 \mathrm{~mm}$ as shown in Figure 8 (case EXP 6-10) and less for bead size $d=10 \mathrm{~mm}$ as shown in Figure 14 (case EXP 10-10). Due to lower infiltration rate for bead size $d=6 \mathrm{~mm}$ compared to bead size $d=10 \mathrm{~mm}$, the surface of the water at location near the gate recedes slower than the case with bead size $d=10 \mathrm{~mm}$ and therefore the area of the water subjected to gate friction and pulling effect is larger.

As can been seen in Figure 5 to Figure 16, the numerical model agrees very well with the experiment result for the reproduction of surface water profile between the receding upstream travelling wave and the upstream wall. The forward propagating front wave which is travelling on porous surface also shows good agreement with experiment results in in terms of propagation speed and surface water profile in the porous bed region even though the average infiltration rate (which was obtained from the experiment) is used in the numerical model. 


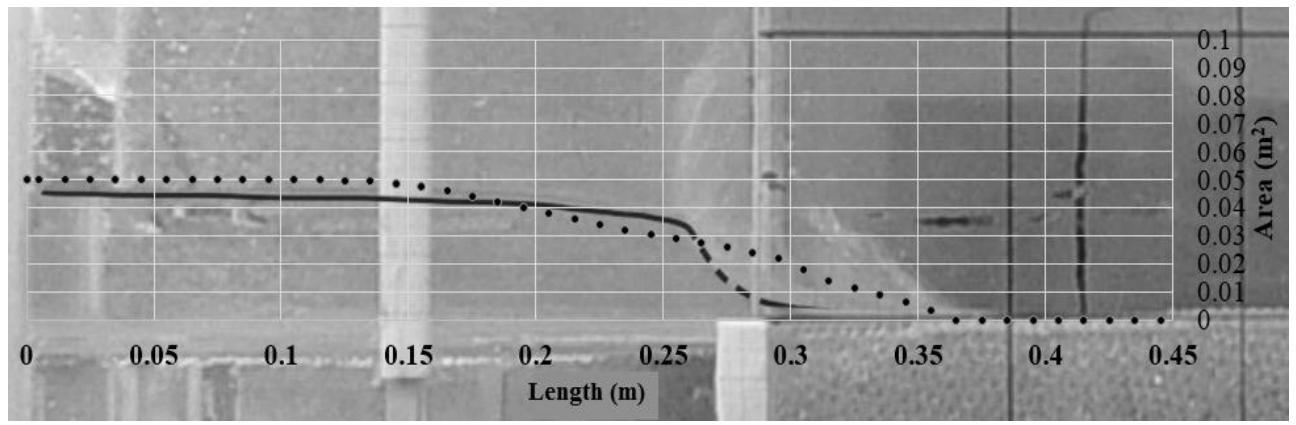

Fig. 5. Numerical simulation (dotted) and experiment with $6 \mathrm{~mm}$ beads, $h_{o}=0.05 \mathrm{~m}$ and $\mathrm{t}=0.2 \mathrm{~s}$.

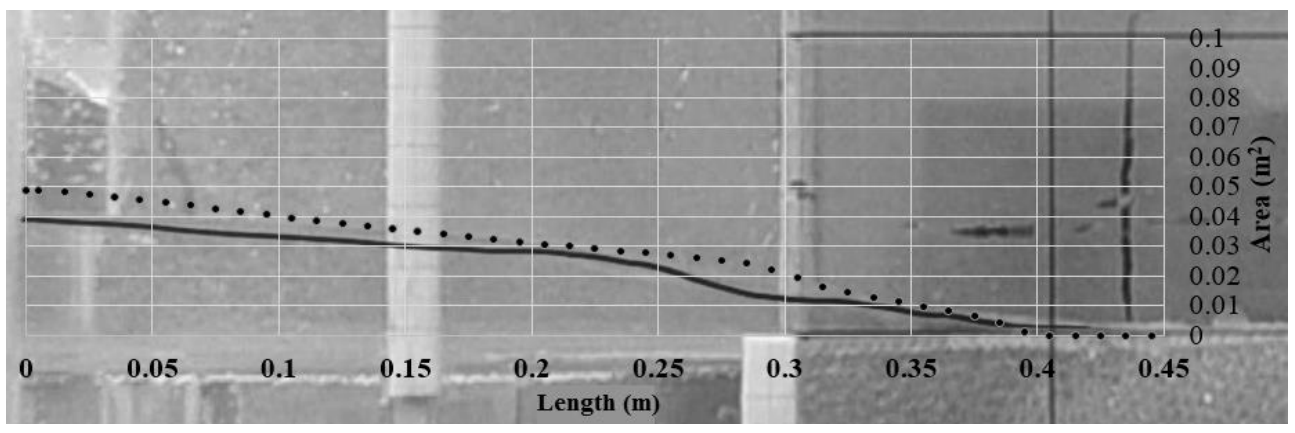

Fig. 6. Numerical simulation (dotted) and experiment with $6 \mathrm{~mm}$ beads, $h_{o}=0.05 \mathrm{~m}$ and $\mathrm{t}=0.4 \mathrm{~s}$.

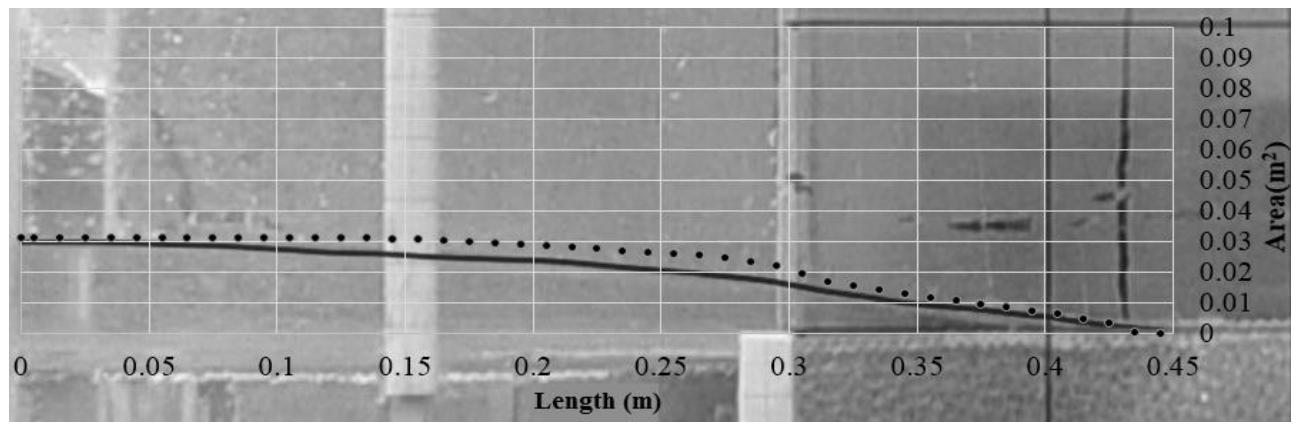

Fig. 7. Numerical simulation (dotted) and experiment with $6 \mathrm{~mm}$ beads, $h_{o}=0.05 \mathrm{~m}$ and $\mathrm{t}=0.6 \mathrm{~s}$.

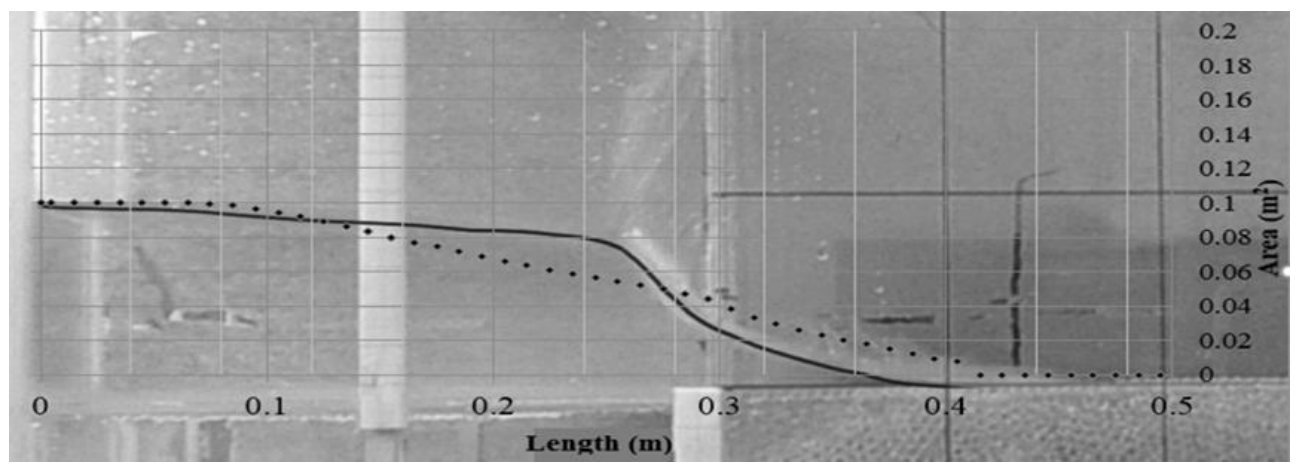

Fig. 8. Numerical simulation (dotted) and experiment with $6 \mathrm{~mm}$ beads, $h_{o}=0.10 \mathrm{~m}$ and $\mathrm{t}=0.2 \mathrm{~s}$. 


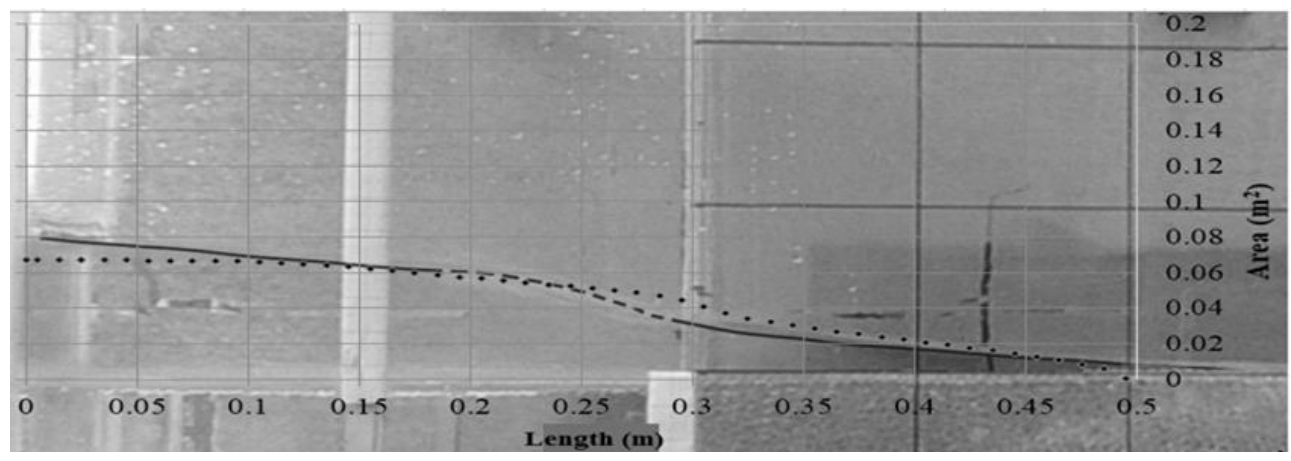

Fig. 9. Numerical simulation (dotted) and experiment with $6 \mathrm{~mm}$ beads, $h_{o}=0.10 \mathrm{~m}$ and $\mathrm{t}=0.4 \mathrm{~s}$.

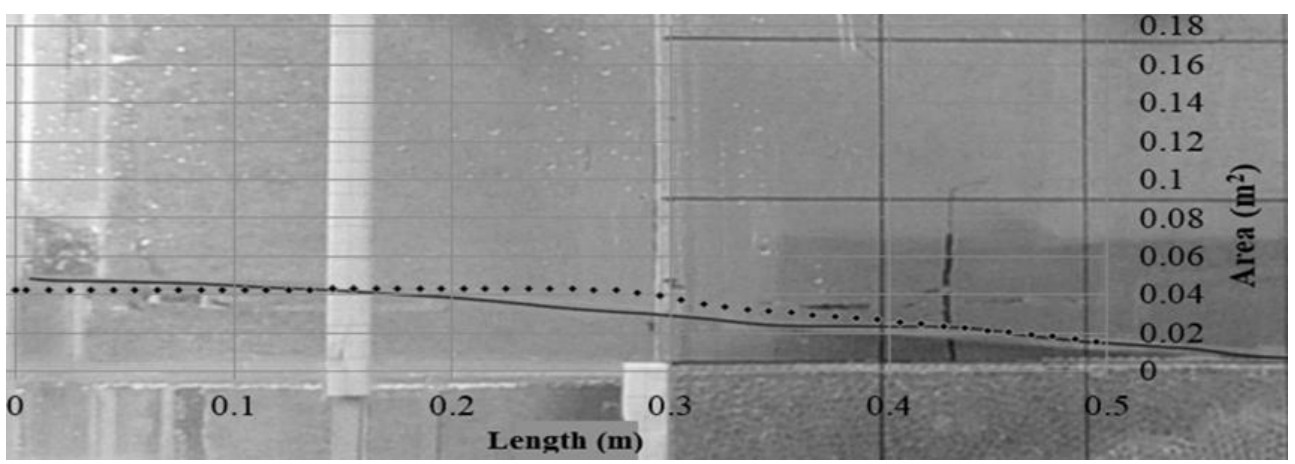

Fig. 10. Numerical simulation (dotted) and experiment with $6 \mathrm{~mm}$ beads, $h_{o}=0.10 \mathrm{~m}$ and $\mathrm{t}=0.6 \mathrm{~s}$.

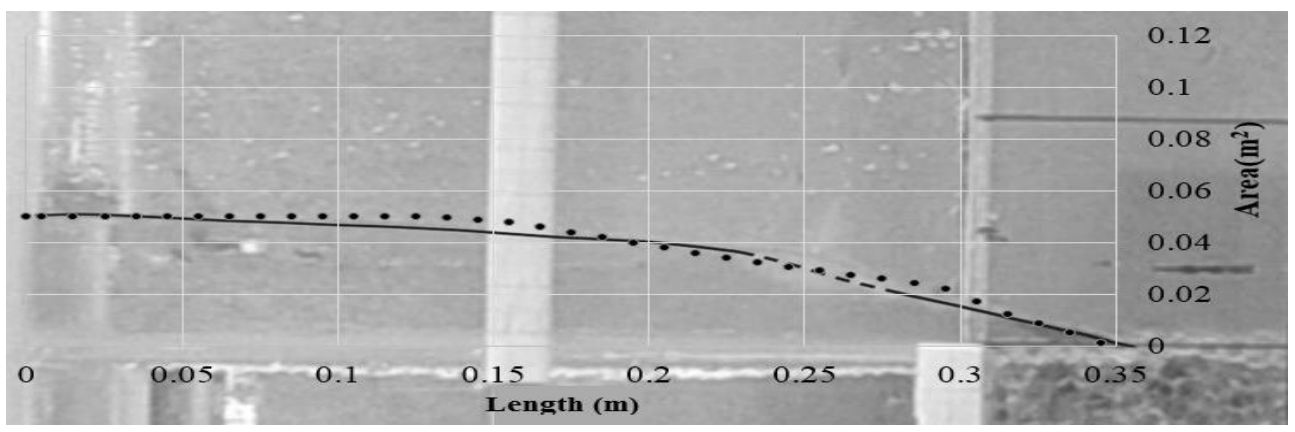

Fig. 11. Numerical simulation (dotted) and experiment with $10 \mathrm{~mm}$ beads, $h_{o}=0.05 \mathrm{~m}$ and $\mathrm{t}=0.2 \mathrm{~s}$. 


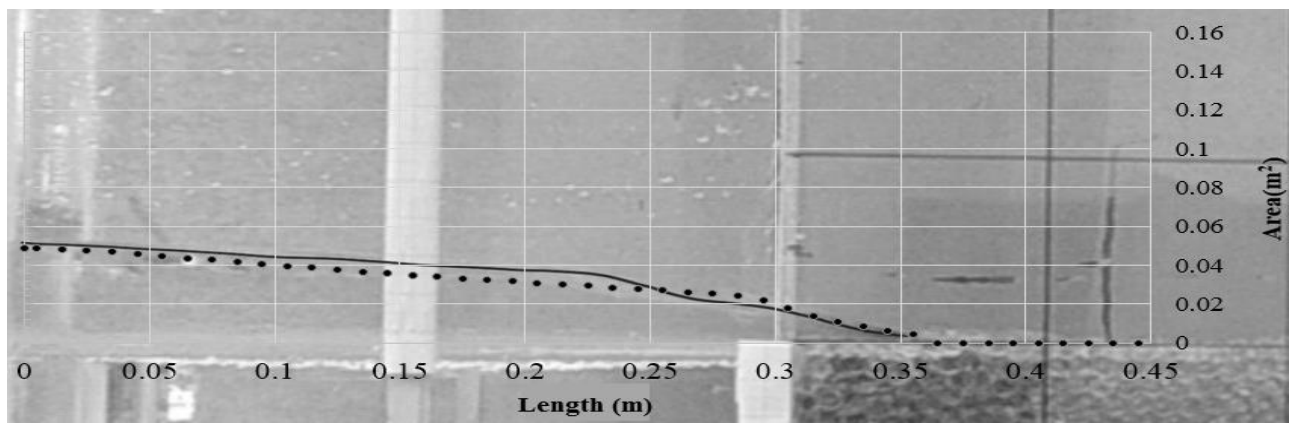

Fig. 12. Numerical simulation (dotted) and experiment with $10 \mathrm{~mm}$ beads, $h_{o}=0.05 \mathrm{~m}$ and $\mathrm{t}=0.4 \mathrm{~s}$.

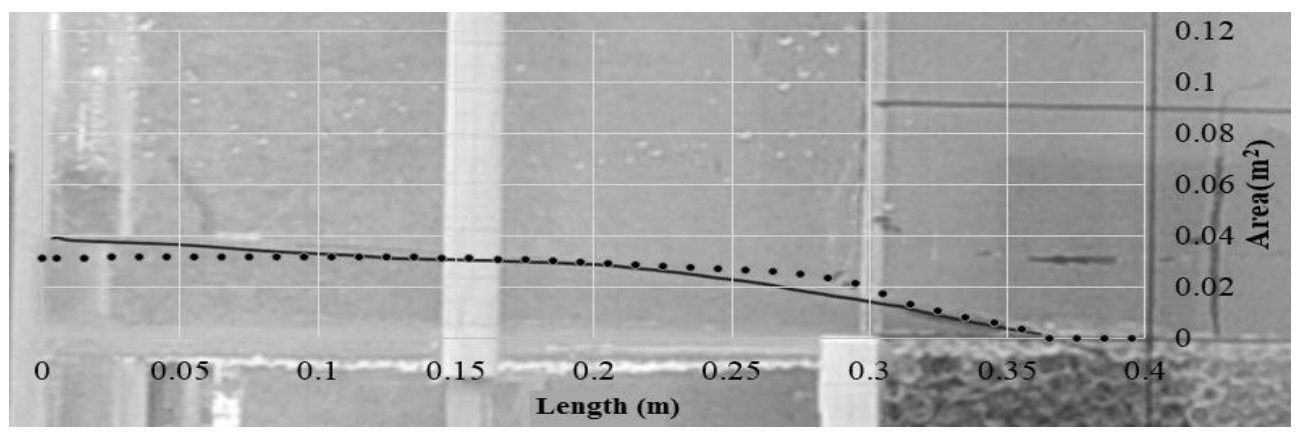

Fig. 13. Numerical simulation (dotted) and experiment with $10 \mathrm{~mm}$ beads, $h_{o}=0.05 \mathrm{~m}$ and $\mathrm{t}=0.6 \mathrm{~s}$.

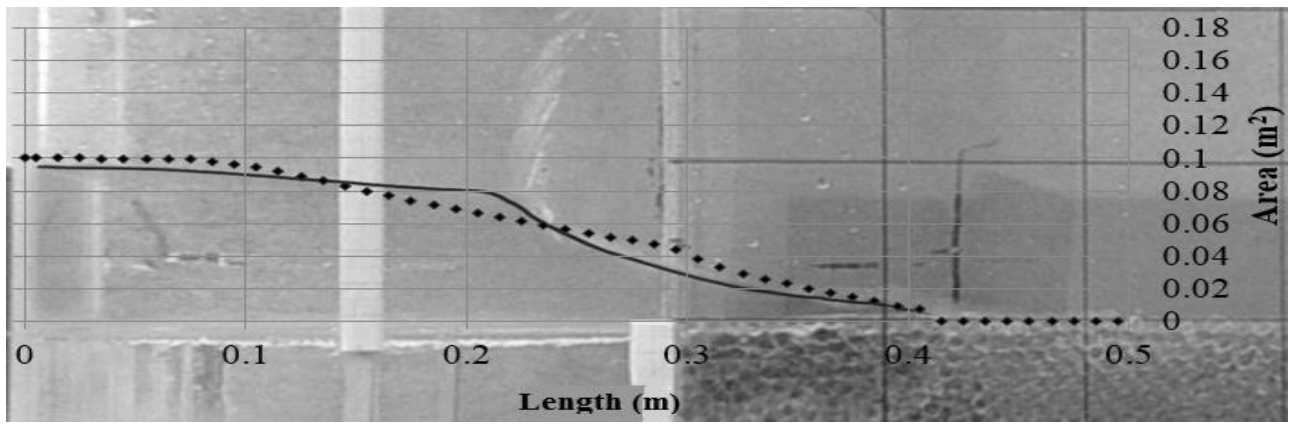

Fig. 14. Numerical simulation (dotted) and experiment with $10 \mathrm{~mm}$ beads, $h_{o}=0.10 \mathrm{~m}$ and $\mathrm{t}=0.2 \mathrm{~s}$.

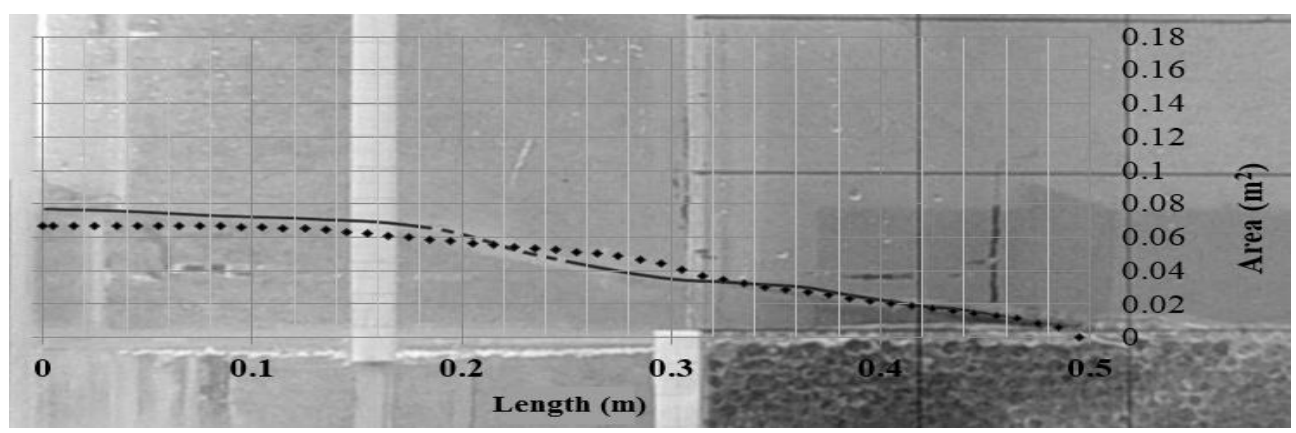

Fig. 15. Numerical simulation (dotted) and experiment with $10 \mathrm{~mm}$ beads, $h_{o}=0.10 \mathrm{~m}$ and $\mathrm{t}=0.4 \mathrm{~s}$. 


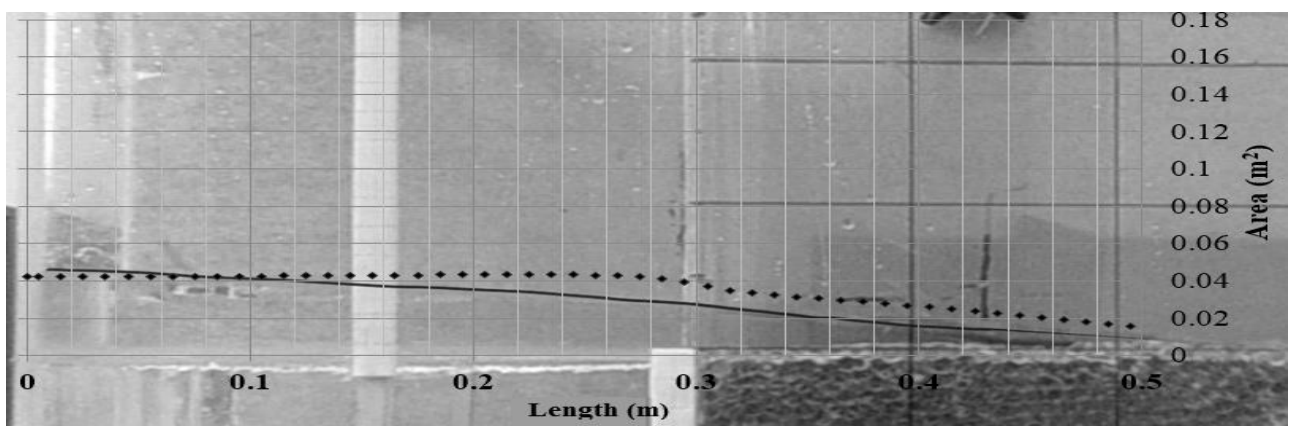

Fig. 16. Numerical simulation (dotted) and experiment with $10 \mathrm{~mm}$ beads, $h_{o}=0.10 \mathrm{~m}$ and $\mathrm{t}=0.6 \mathrm{~s}$.

\section{Conclusion}

A higher order one-dimensional depth average model is developed in this study to simulate the flow over porous media. It was shown that the accuracy of the numerical model can be improved by using the third order Constrained Interpolation Profile (CIP) scheme to solve the advection terms in the of depth-averaged continuity and momentum equations. By using the averaged infiltration rate, the numerical model was able to produce satisfactory result when compared to the experiment data, especially in terms of the reproduction of the overall flow profile and front propagation speed. The one-dimensional model is useful for the simulation of one-dimensional flow in swale system. It can also be easily extended into a twodimensional model for wider application.

\section{References}

1. M. Marchiomi, G. Becciu, Int J. Sus.Dev.\& Planning, 10, 6, 806-817 (2015)

2. R. Dearden, S. Price, CCWI 2011: Computing and Control for the Water Industry (2011)

3. J. Ossa-Moreno, K. M. Smith, A. Mijic, Sus. Cities \& Society, 28, 411-419 (2017)

4. T. Yabe, H. Mizoe, K. Takizawa, H. Moriki, H. N. Im, Y. Ogata, J. Comp. Phy. 194, 1, 57-77 (2004)

5. H. Chanson, The hydraulics of open channel flow: an introduction (Elsevier Butterworth Heinemann, Oxford, 2004)

6. O. Castro-Orgaz, H. Chanson, Environ Fluid Mech, 17, 665-694 (2017) 